\title{
Re-examination of aftershocks of the 1952 Tokachi-oki earthquake and a comparison with those of the 2003 Tokachi-oki earthquake
}

\author{
Nobuo Hamada ${ }^{1}$ and Yasunori Suzuki ${ }^{2}$ \\ ${ }^{1}$ Meteorological Research Institute, 1-1, Nagamine, Tsukuba 305-0052, Japan \\ ${ }^{2}$ Association for the Development of Earthquake Prediction, 1-5-18 Sarugaku-cho, Chiyoda-ku, Tokyo 101-0064, Japan
}

(Received November 26, 2003; Revised February 3, 2004; Accepted February 25, 2004)

\begin{abstract}
We relocated hypocenters of the March 4, 1952 Tokachi-oki $\left(M_{j} 8.2\right)$ earthquake and its aftershocks by reassessing data of the Central Meteorological Station network at the time and found that the distribution of relocated aftershocks is clearly bounded on its eastern extension by the Kushiro canyon, which extends south-east from the coast of Hokkaido near Kushiro to the Kuril trench. The reevaluated aftershock pattern is quite similar to the pattern of the September 26, 2003 Tokachi-oki earthquake $\left(M_{j} 8.0\right)$. Detailed seismic intensity maps based on the report of human perceptions in 1952 and the seismic intensity meter network in 2003 also show resemblance. Similar aftershock pattern and seismic intensity distribution imply that both earthquakes are a pair of characteristic earthquakes of the same size sharing the same source area and the same focal process.
\end{abstract}

Key words: Tokachi-oki, seismic gap, asperity, characteristic earthquake, aftershock, characteristic earthquake, seismic Intensity, seismic gap.

\section{Introduction}

Seismicity gaps found along the subducting plate boundary have been considered as potential sources of the future great inter-plate earthquake. Based on the seismicity gap hypothesis, Mogi (1969) and Utsu (1972) pointed out a potential of the $M 8$ class earthquake occurrence in the region south west of the Nemuro peninsula in eastern Hokkaido island, Japan between the focal regions of the March 4, 1952 Tokachi-oki earthquake $\left(M_{j} 8.2\right)$ and the August 12, 1969 Shikotan earthquake $\left(M_{j} 7.8\right)$ (Fig. 1). In the meantime, when the June 17,1973 Nemuro-oki earthquake $\left(M_{j} 7.4\right)$ occurred, it became a controversial issue whether the Nemurooki earthquake was the expected event that filled the seismicity gap since the magnitude of the earthquake $\left(M_{j} 7.4\right)$ determined by the Japan Meteorological Agency (JMA) was not so large as a typical great inter-plate earthquake and the aftershocks only filled the coastal half of the gap. Based on the revised aftershock pattern of the 1952 Tokachi-oki earthquake, Sekiya et al. (1974) reported that the offshore area region of the gap was already filled by aftershocks of the 1952 Tokachi-oki earthquake and the plate boundary of the region was uniformly filled by the aftershocks of great earthquakes (Fig. 2(a)). Recent study of the source of the 1952 Tokachioki earthquake based on the inversion of tsunami waveforms by Hirata et al. (2003) estimated a significant tsunami generating source in the offshore region of the Nemuro peninsula consistent to those inferred from the aftershock distribution by Sekiya et al. (1974).

In contrast with the original distribution shown in Fig. 2(b) located by the Central Meteorological Observatory (abbrevi-

Copy right(c) The Society of Geomagnetism and Earth, Planetary and Space Science (SGEPSS); The Seismological Society of Japan; The Volcanological Society of Japan; The Geodetic Society of Japan; The Japanese Society for Planetary Sciences; TERRAPUB ated CMO here after) (1953), Sekiya et al. (1974) located many aftershocks in the region east of the Kushiro canyon, a prominent bathymetry, offshore area of the aftershock zone of the 1973 Nemuro-oki earthquake (Fig. 2(a)). However, considering the timing accuracy of data in 1952, we suspect that it might include larger location errors. Accordingly, we reinvestigated the seismicity related to the 1952 Tokachi-oki earthquake and compared it with data of the September 26, 2003 Tokachi-oki earthquake.

\section{Relocation of the 1952 Event}

Seismic stations of the Central Meteorological Observatory in 1952 are indicated in Fig.3. To pin-point hypocenters by the data available from the old seismological observation network, which consisted of mechanical instruments, we need careful evaluation about the quality of seismic data. In the recent effort in progress for improvement of the earthquake catalog of the Japan Meteorological Agency (Hamada et al., 2002), we have been adopting the most appropriate hypocenter location method depending on the timing accuracy of phase arrivals and the azimuthal coverage of stations around epicenters. Conventional hypocenter location is a process for finding a position where rms residual of observed and theoretically expected arrivals of $P$ and $S$ waves has a minimum value. For data registered after 1960s, when crystal chronometers were introduced in the observation, there is little room to doubt that hypocenter location using absolute $P$ and $S$ arrival times provides the most reliable hypocenters. However due to poor time keeping of the network, for data of early observations such as the aftershocks of the 1923 Kanto earthquake, there was no alternative but to use $S$ - $P$ times for hypocenter location (Hamada et al., 2000) since $S$ - $P$ times are insensitive to timing accuracy. To establish location during the period in between, the combination of $P, S$ arrivals 


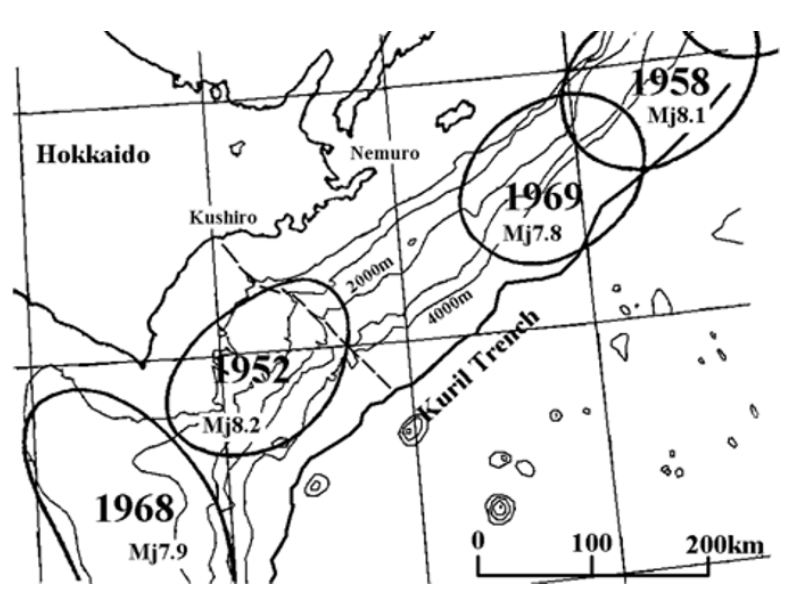

Fig. 1. Distribution of sources of inter plate earthquakes and seismicty gap along the western part of the Kuril trench immediate before the occurrence of the June 17, 1973 Nemuro-oki earthquake (Mj7.4). Dashed line from the coast near Kushiro indicate the Kushiro sea canyon. Magnitudes $\mathrm{Mj}$ is determined by the Japan Meteorological Agency. Source regions of the 1952 Tokachi-oki earthquake (Mj8.2), the 1958 Etrofu earthquake (Mj8.1), the 1969 Shikotan earthquake (Mj7.8) and the 1968 Tokachi-oki earthquake (Mj7.9) are indicated. The figure is taken and modified from Utsu (1972).
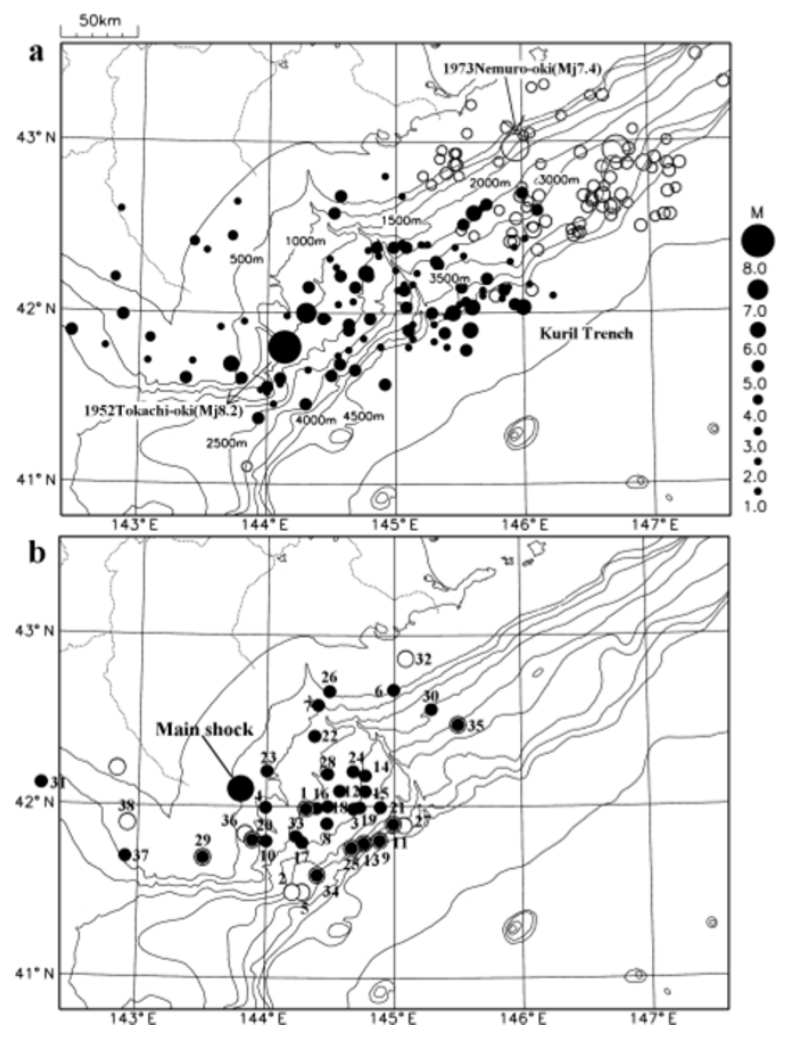

Fig. 2. The upper figure (a) shows aftershocks occurring within one month period after the 1952 Tokachi-oki earthquake (closed circles) reported by Sekiya et al. (1974) and those of the 1973 Nemuro-oki earthquake (open circles) reported by JMA (1973). The lower figure (b) shows aftershocks of the 1952 Tokachi-oki earthquake initially located by the CMO (1953) using a graphical location method. Numbers indicate an order of occurrence of aftershocks listed in CMO (1953).

and $S$ - $P$ times provides the most reliable hypocenters which

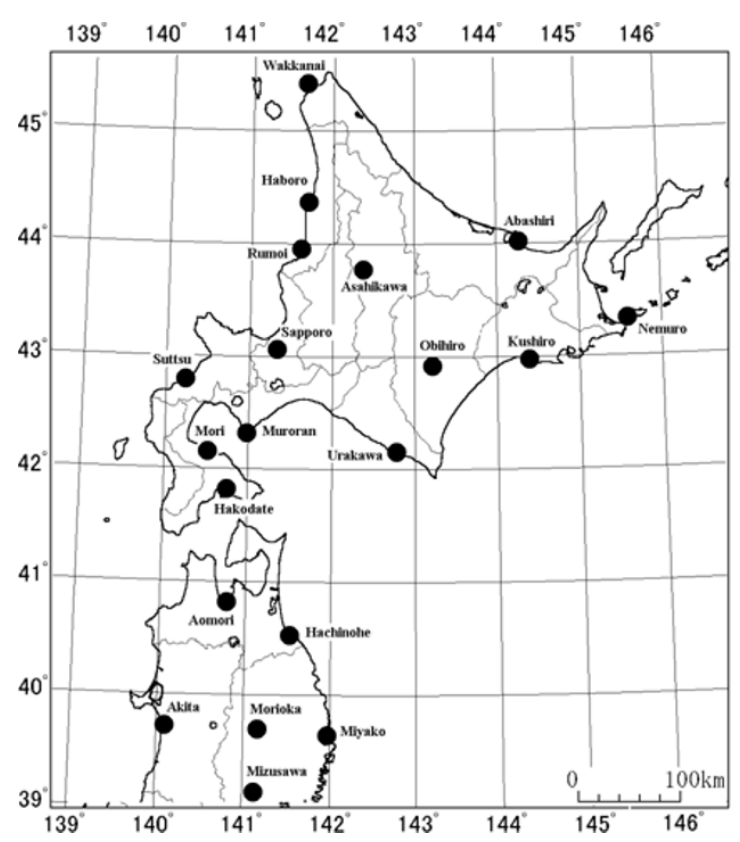

Fig. 3. Seismic stations located around the source region of the 1952 Tokachi-oki earthquake operated by the Central Meteorological Observatory in 1952.

minimizes rms residuals expressed by the formula (1),

$$
\begin{aligned}
\mathrm{Rms}= & \sum_{i=1}^{n} W_{p}^{2}\left(O_{p}-C_{p}\right)_{i}^{2}+\sum_{i=1}^{n} W_{s}^{2}\left(O_{s}-C_{s}\right)_{i}^{2} \\
& +\sum_{k=1}^{m} W_{s p}^{2}\left(O_{s-p}-C_{s-p}\right)_{k}^{2}
\end{aligned}
$$

where $O$ and $C$ respectively indicate observed and calculated phase arrivals respectively and $W$ indicate their weights. Subscripts $p, s$ and $s$ - $p$ respectively denote values for $P$, $S$ arrivals and $S$ - $P$ times, and $i$ and $k$ indicate stations. The first and second terms are respectively for $P$ and $S$ phase data for stations where time keeping of the observation seems to be reliable. The last term is for $S-P$ times of stations where time keeping was poor absent. The majority of phase data after 1930s seem to be reliable enough to be fed in the first and second terms in the formula (1) for hypocenter location. However, due to insufficient instrumentation or other specific reasons, time keeping of some stations had been not always reliable and strong earthquakes or earthquake swarms tend to temporally disturb the operation of the network since mechanical clocks were susceptible to ground shaking. Time keeping of the observation depends on several conditions such as stability of timing clocks, condition on reception of standard time broadcasting and fluctuation of recording drum rotation etc. Minor timing errors in phase data reading generates large errors in epicenter location or provide unreasonable focal depth when all stations were remote from the epicenter and azimuthal coverage of the station was insufficient, especially in the offshore region around Japanese archipelago. Appropriate use of $S$ - $P$ times in (1) for selected stations provides better hypocenter solution in such a cases.

We initially used $S$ - $P$ times of stations indicated in Fig. 3 for relocation of all aftershocks and in the next step, we used 
absolute $P$ and $S$ arrivals in relocation and compared the results with each other. If time keeping of the network is better, hypocenters located using $P$ and $S$ arrivals and those located using $S$ - $P$ times should show good agreement. If the difference is small and focal depth is reasonably shallow as an aftershock, we take the hypocenter using $P$ and $S$ arrivals as the final solution.

If the difference is larger, we carefully examined travel time residuals of individual station and examined whether the data should be eliminated from the location or not. Although it is difficult to define clear criteria for data screening, we eliminated data with residuals larger than about 2 sec. Large travel time residuals are occasionally found among data from stations nearest to the focal area, such as Obihiro, Nemuro, Abashiri and Urakawa in eastern Hokkaido. Poor correlations of travel time residuals of specific stations for successive events suggest that large residuals are originated from causes such as irregular feeding speed of seismograms and difficulty in phase identification from low magnification seismograms, rather than systematic errors originated from timing clocks. Among data eliminated from hypocenter location we selected data with large travel time residuals for both $P$ and $S$ arrivals but small residual for $S$ - $P$ time for further improvement using the last term of the formula (1) and determined the final solution of hypocenters. In the worst case when it was difficult to classify the quality of data, we used the $S$ - $P$ location.

\section{Discussions}

\section{Comparison with previous studies}

By using the experimental procedure mentioned above, we relocated hundreds of aftershock of the 1952 Tokachi-oki earthquake. The relocated aftershocks, which show large discrepancy in epicentral position with those reported by Sekiya et al. (1974), are indicated in Fig. 4. The main shock and all the relocated aftershocks during the period from March 4 to April 4, 1952 are indicated in Fig. 5. Aftershocks of the 1952 Tokachi-oki earthquake originally reported by CMO (1953) (Fig. 2(b)) were manually located by a graphical location method using $S$ - $P$ times. After JMA introduced electronic computers for hypocenter location in 1961, Sekiya et al. (1974) relocated the 1952 Tokachi-oki earthquake and its aftershocks as shown in Fig. 2(a) by using $P$ and $S$ arrival times assuming that timing accuracy of the C.M.O network in 1950s has been much improved. A general doubt about validity of computer located hypocenters has also been reported by Motoya (2000).

Figure 5 indicates that epicenters relocated by the present study are showing good similarity to those in Fig. 2(b) reported by CMO (1953), although more aftershocks were located by the present study. The results suggests that aftershock regions don't extend to the east of the Kushiro canyon and there is a seismicty gap between the aftershock zone of the 1952 Tokachi-oki earthquake and those of the 1973 Nemuro-oki earthquake. It is not in the scope of this study to decide whether the seismicity gap is a potential source of future inter-plate earthquake. However, eastward extension of the after slip of the 2003 Tokachi-oki earthquake detected by GPS observation is suggesting a weak coupling of the plate boundary in this region (GSI, 2003).

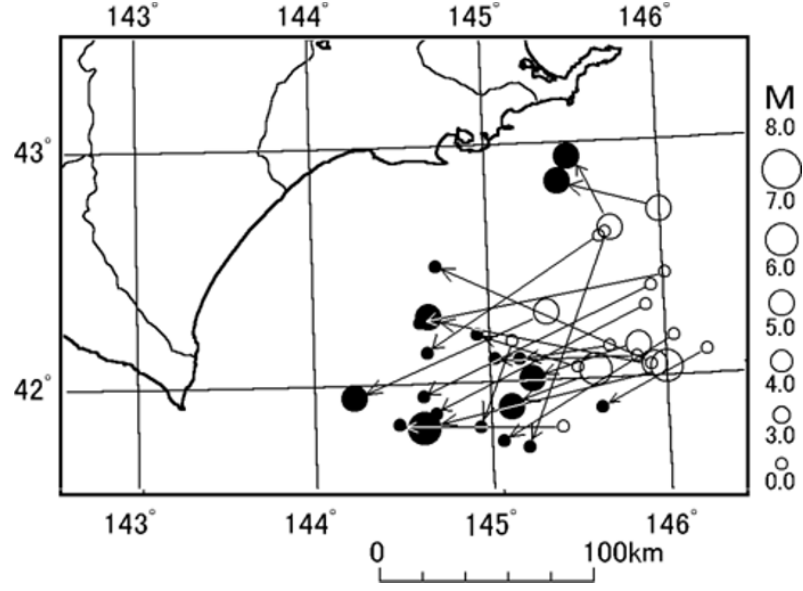

Fig. 4. Examples of discrepancy of epicenters reported by Sekiya et al (1974) (open circles) and those relocated by the present study mainly using S-P times (solid circles). Difference must be originated from poor timing control found among the stations in eastern Hokkaido nearest to the source region of the 1952 Tokachi-oki earthquake.

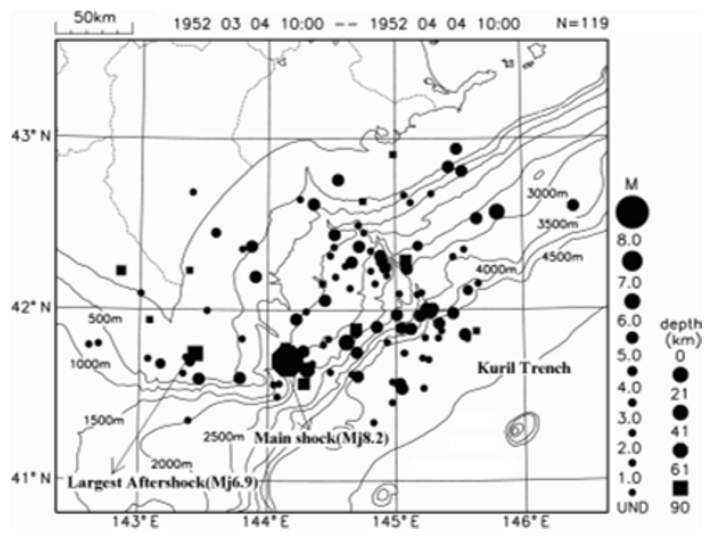

Fig. 5. Relocated aftershocks of the 1952 Tokachi-oki earthquake by the present study. The main shock and aftershocks occurring within one month period are shown.

\section{Comparison of the aftershock zone of the 1952 and the 2003 Tokachi-oki earthquake}

Hypocenters of the March 4, 1952 Tokachi-oki earthquake and the September 26, 2003 Tokachi-oki earthquake are compared in Fig. 6. The main shock hypocenter of the 2003 Tokachi-oki earthquake determined by the Japan Meteorological Agency is quite close to the main shock hypocenter of the 1952 event. When location errors of both events are concerned, it should be noted that both earthquakes originated from the same place. The positions of the largest aftershocks of both earthquakes respectively occurring on March 10 in 1952 and on September 26 in 2003 are located west of the mainshocks and also close to each other. Distribution of aftershocks of both events show good resemblance to each other.

A source rupture process study by Yamanaka and Kikuchi (2004) suggested similarity in focal process of both earthquakes. They also noted that the aftershocks of the 2003 event are distributed around the asperity. A source characteristic such as rupture directivity should be reflected also on the seismic intensity distribution. Seismic intensity distribution 

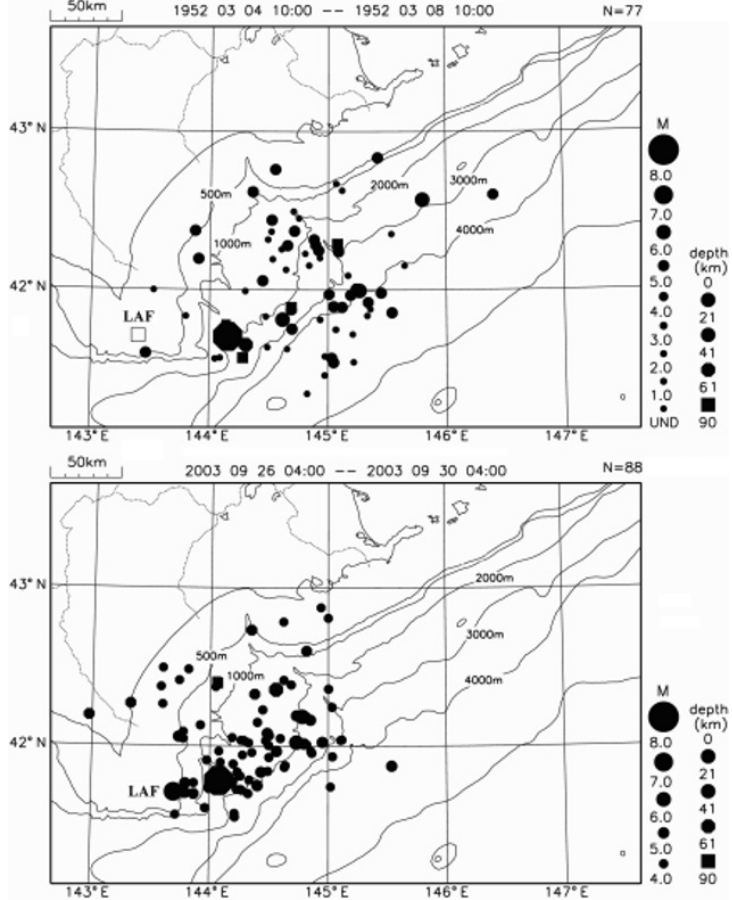

Fig. 6. Comparison of aftershocks occurring within 4 days period after the mainshock of the 1952 Tokachi-oki earthquake and the 2003 Tokachi-oki earthquake. The largest aftershocks of the 1952 earthquake (indicated as LAF in the figure) occurring on 10 March, six days after the mainshock, is also indicated by open square.

of the 1952 Tokachi-oki earthquake based on the human perception reports (eyewitness accounts) by CMO (1953) was compared with data of the 2003 earthquake obtained by the seismic intensity data from the network of JMA and local governments in Fig. 7 . Although seismic intensity of the 2003 earthquake seems to be slightly larger in average than those of the 1952 earthquake, the pattern of the intensity distribution looks similar. Larger intensity values due to soft sediment are recognized in both cases as observed in the Tokachi Plain.

While the moment magnitude $\left(M_{\mathrm{w}}\right)$ of the 1952 earthquake was estimated 8.1 by Kanamori and Anderson (1975) and Hirata et al. (2003), the $M_{\mathrm{w}}$ of the 2003 event was estimated as 8.0 by Yamanaka and Kikuchi (2003) suggesting that the size of the 1952 earthquake somewhat larger than the 2003 earthquake. As Kiyono et al. (2001) noted, the relation between conventional seismic intensity determined by human perception and instrumental seismic intensity is currently a hot issue of engineering seismology. In spite of the fact that the instrumentally determined magnitude of the 1952 Tokachi-oki earthquake is larger than the 2003 earthquake, the slightly larger seismic intensity values of the 2003 earthquake is suggesting a possibility of a systematic biasing between both scales. Similarity detected in the aftershock distribution and seismic intensity distribution of both earthquakes supports that they both are recurrent earthquakes with the same source area and the same rupture process.

\section{Conclusion}

Careful examination of the quality of phase readings of the 1952 Tokachi-oki earthquake and its aftershocks obtained by

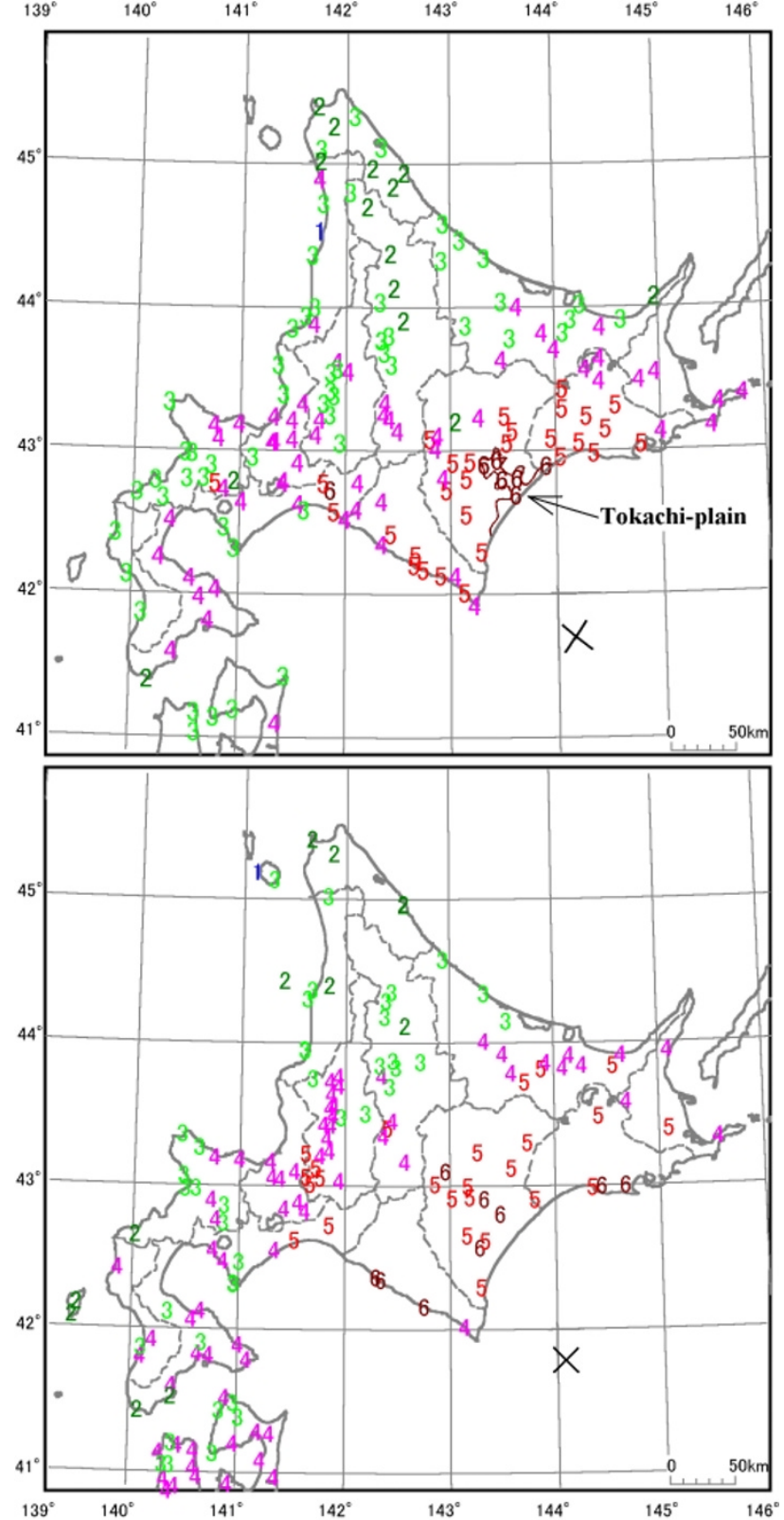

Fig. 7. Detailed seismic intensity distribution of the 1952 Tokachi-oki earthquake (upper figure) and those of the 2003 Tokachi-oki earthquake (lower figure). The distribution of seismic intensity in the JMA seismic intensity scale (0-7) for the 1952 earthquake is after CMO (1952) and those for the 2003 is based on the observation of seismic intensity meters operated by the Japan Meteorological Agency and local governments. X marks indicate epicenter of the main shocks.

the seismological observation network of the Central Meteorological Observatory indicated diversity of timing accuracy of the data. We relocated hypocenters using $P$ and $S$ arrival times or $S$ - $P$ times depending on the condition of time keeping at each station in each earthquake. The aftershocks were previously thought to extend from south west to northeast landwards of the Kuril trench and to fill the offshore region of the Nemuro peninsula between the focal region of the 1973 Nemuro-oki earthquake which is consistent to the seismic gap hypothesis for earthquake occurrence in the subduction zone. The relocated aftershock zone is, however, smaller and clearly bounded on its eastern extension by the 
Kushiro canyon, south-east from the coast of Hokkaido near Kushiro to the Kuril trench.

The reassessed aftershock pattern is compared with the September 26, 2003 Tokachi-oki earthquake. Both earthquakes show good similarity in the position of the mainshocks, and the largest aftershocks and the aftershock patterns. Detailed seismic intensity maps based on the report of human perceptions in 1952 and the seismic intensity meter network in 2003 also demonstrate resemblance. Similar aftershock pattern and seismic intensity distribution impliy that both earthquakes are a pair of characteristic earthquakes of the same size, which occurred recurrently in the same source area with the same focal process.

Acknowledgments. Seismic phase reading data of Japan available from the seismological network of the Central Meteorological Observatory has been archived in the Japan Meteorological Agency. Conversion of the old data into a computer readable format has been promoted by auspices of the Association for the Development of Earthquake Prediction (ADEP). We would like to express our sincere thanks for the continuous support of the ADEP that enabled this work.

\section{References}

Central Meteorological Observatory (CMO), Report of the Tokachi-Oki earthquake of March 4, 1952, Q. J. Seismol., 17, 135 pp., 1953 (in Japanese).

GSI, Horizontal afterslip of the 2003 Tokachi-oki earthquake, reported at 154th meeting of the Coordinating Committee for Earthquake Prediction (CCEP), 2003.

Hamada, N., K. Yoshikawa, M. Nishiwaki, M. Abe, and F. Kusano, A comprehensive study of aftershocks of the 1923 Kanto earthquake, $J$.
Seismol. Soc. Japan, 54, 251-265, 2001.

Hamada, N., K. Yoshikawa, S. Kondo, N. Kamaya, T. Aketagawa, Y. Suzuki, and R. Matsu'ura, Extension and revise of the earthquake catalog of the Japan Meteorological Agency, Programme and abstract of the Joint meeting of earth and planetary science, S047-001, 2002.

Hirata, K., E. Geist, K. Satake, Y. Tanioka, and S. Yamaki, Slip distribution of the 1952 Tokachi-Oki earthquake (M8.1) along the Kuril trench deduced from tsunami waveform inversion, J. Geophys. Res., 108, 2196, doi:10.1029/2002JB001976, 2003.

Japan Meteorological Agency, The seismological bulletin of the Japan Meteorological Agency for June-July 1973, 1973.

Kanamori, H. and D. L. Anderson, Theoretical basis of some empirical relations in seismology, Bull. Seism. Soc. Am., 65, 1073-1095, 1975.

Kiyono, J., K. Toki, T. Usuda, and Y. Ohta, 2001, Engineering Characterization of Instrumental Seismic Intensity and Importance of Introducing Multi-valued Seismic Intensity, Proc. Japan Soci. Civil Engineers, No. 628/I-56, pp. 267-278.

Mogi, K., Some features of recent seismic activity in and near Japan (2), Activity before and after great earthquakes, Bull. Earthq. Res. Inst., 47, 395-427, 1969.

Motoya, Y., Reexamination of seismic gaps before the 1952 Tokachi-oki earthquake and the 1973 Nemuro-hanto-oki earthquake, Geophys. Bull. Hokkaido Univ., 63, 23-32, 2000.

Sekiya, H., S. Hisamoto, E. Mochizuki, E. Kobayashi, T. Kurihara, K. Tokunaga, and M. Kishio, The off Nemuro Peninsula earthquake of 1973 and the large earthquakes off southern part of Hokkaido, Q. J. Seosmol., 39, 33-39, 1974 (in Japanese with English abstruct).

Ustu, T., Large earthquakes near Hokkaido and the expectancy of the occurrence of a large earthquake off Nemuro, Rep. Cord. Comm. Earthquake Predict. 7, pp. 7-13 (in Japanese with English figure caption).

Yamanaka, Y. and M. Kikuchi, Source process of the recurrent Tokachioki earthquake on September 26, 2003, inferred from teleseismic body waves, Earth Planets Space, 55, e21-e24, 2003.

N. Hamada (e-mail: hamada.nobuo@nifty.ne.jp) and Y. Suzuki 